Review Article

\title{
Upper Tract Urothelial Carcinomas in Patients with Chronic Kidney Disease: Relationship with Diagnostic Challenge
}

\author{
Li-Jen Wang, ${ }^{1,2,3}$ Shen-Yang Lee, ${ }^{4,5}$ Bin Tean Teh, \\ Cheng-Keng Chuang, ${ }^{5,7}$ and Joëlle Nortier ${ }^{8}$ \\ ${ }^{1}$ Department of Medical Imaging and Intervention, Linkou Chang Gung Memorial Hospital, 5 Fu-Hsing Street, \\ Gueishan, Taoyuan 33333, Taiwan \\ ${ }^{2}$ Department of Medical Imaging and Radiological Sciences, College of Medicine, Chang Gung University, Taoyuan 33333, Taiwan \\ ${ }^{3}$ Institute of Radiological Research, College of Medicine, Chang Gung University, Taoyuan 33333, Taiwan \\ ${ }^{4}$ Department of Nephrology, Linkou Chang Gung Memorial Hospital, Taoyuan 33333, Taiwan \\ ${ }^{5}$ Department of Medicine, College of Medicine, Chang Gung University, Taoyuan 33333, Taiwan \\ ${ }^{6}$ National Cancer Center and Duke-NUS Graduate Medical School, Singapore 169610 \\ ${ }^{7}$ Department of Urology of Linkou Chang Gung Memorial Hospital, Taoyuan 33333, Taiwan \\ ${ }^{8}$ Department of Nephrology, Erasme Hospital, 1070 Brussels, Belgium
}

Correspondence should be addressed to Li-Jen Wang; lijenwang0918@gmail.com

Received 23 April 2014; Revised 20 July 2014; Accepted 23 July 2014; Published 7 August 2014

Academic Editor: Sivagnanam Thamilselvan

Copyright (C) 2014 Li-Jen Wang et al. This is an open access article distributed under the Creative Commons Attribution License, which permits unrestricted use, distribution, and reproduction in any medium, provided the original work is properly cited.

\begin{abstract}
Chronic kidney disease and upper tract urothelial carcinomas display a bidirectional relationship. Review of the literature indicates that early diagnosis and correct localization of upper tract urothelial carcinomas in dialysis patients and kidney transplant recipients are important but problematic. Urine cytology and cystoscopy have limited sensitivity for the diagnosis of upper tract urothelial carcinomas in dialysis patients. Enhanced computed tomography and magnetic resonance imaging could prove useful for the detection and staging of upper tract urothelial carcinomas in dialysis patients. Renal ultrasound can detect hydronephrosis caused by upper tract urothelial carcinomas in kidney transplant recipients but cannot visualize the carcinomas themselves. High detection rates for upper tract urothelial carcinomas in kidney transplant recipients have recently been demonstrated using computed tomography urography, which appears to be a promising tool. To detect carcinomas in dialysis patients and kidney transplant recipients as early as possible, regular screening in asymptomatic patients and diagnostic work-up in symptomatic patients should be performed using a combination of urological and imaging methods. Careful assessment of subsequent recurrence within the contralateral upper urinary tract and the urinary bladder is necessary for dialysis patients and kidney transplant recipients with upper tract urothelial carcinomas.
\end{abstract}

\section{Introduction}

Chronic kidney disease (CKD) is characterized by the presence of kidney damage or decreased kidney function with a glomerular filtration rate of $<60 \mathrm{~mL} / \mathrm{min} / 1.73 \mathrm{~m}^{2}$ for at least 3 months, irrespective of the cause [1]. The definition of CKD underwent minor modifications in 2004 and now includes classification based on dialysis treatment or transplantation to denote the special care required for these groups of patients [2].
Upper tract urothelial carcinomas (UTUCs) and CKD are closely associated. High prevalence rates of CKD of 58.6\% and $57.7 \%$ in China and Taiwan, respectively, have been reported in patients with UTUCs $[3,4]$. The high prevalence of CKD in upper tract urothelial carcinoma (UTUC) patients is attributable to old age, aristolochic acid nephropathy, and increased risk status after nephroureterectomy, a standard treatment for UTUCs [5]. Similarly, Hung et al. demonstrated a linear relationship between UTUC prevalence and CKD severity. The prevalence rates of UTUCs in none/mild CKD, 
TABLE 1: Proportions, locations, and gender distribution of urothelial carcinomas in dialysis patients.

\begin{tabular}{|c|c|c|c|c|c|}
\hline \multirow{2}{*}{ Reference (country) } & \multicolumn{3}{|c|}{ Proportions in dialysis patients } & \multicolumn{2}{|c|}{ Proportions in urothelial carcinoma patients } \\
\hline & $\begin{array}{l}\text { Dialysis patients } \\
(n)\end{array}$ & $\begin{array}{c}\text { Urothelial } \\
\text { carcinoma (\%) }\end{array}$ & $\begin{array}{l}\text { Upper tract urothelial } \\
\text { carcinoma }(\%)\end{array}$ & $\begin{array}{l}\text { Female urothelial } \\
\text { carcinoma (\%) }\end{array}$ & $\begin{array}{l}\text { Upper tract urothelial } \\
\text { carcinoma (\%) }\end{array}$ \\
\hline Stewart et al. (Europe) [21] & 296903 & $825(0.3 \%)$ & $165(0.1 \%)$ & NA & $165(20.0 \%)$ \\
\hline $\begin{array}{l}\text { Stewart et al. (Australia and } \\
\text { New Zealand) [21] }\end{array}$ & 13497 & $87(0.6 \%)$ & $34(0.3 \%)$ & NA & $34(39.1 \%)$ \\
\hline Wang et al. (Taiwan) [17] & 10890 & $98(0.9 \%)$ & $31(0.3 \%)$ & $65(66.3 \%)$ & $31(31.6 \%)$ \\
\hline Ou et al. (Taiwan) [25] & 1910 & $17(0.9 \%)$ & $9(0.5 \%)$ & $12(70.6 \%)$ & $9(52.9 \%)$ \\
\hline Chen et al. (Taiwan) [23] & 1333 & $16(1.2 \%)$ & $7(0.5 \%)$ & $9(56.3 \%)$ & $7(43.8 \%)$ \\
\hline Chang et al. (Taiwan) [22] & 1537 & $26(1.7 \%)$ & $14(0.9 \%)$ & $14(53.8 \%)$ & $14(53.9 \%)$ \\
\hline Cuckovic et al. (Serbia) [24] & 923 & $16(1.7 \%)$ & $10(1.1 \%)$ & NA & $10(62.5 \%)$ \\
\hline
\end{tabular}

NA: not available.

stage $3 \mathrm{CKD}$, and stage $4 / 5 \mathrm{CKD}$ are $11 \%, 55 \%$, and $71 \%$, respectively, and these rates are significantly different from each other $(P<0.001)$ [6]. The bidirectional relationship between CKD and UTUCs suggests they may share risk factors.

Several nephrotoxins, including analgesics and aristolochic acid, might explain the bidirectional relationship between CKD and UTUCs in accordance with their nephrotoxic and carcinogenic effects [7]. Abuse of compound analgesic agents (mainly containing phenacetin) is associated with analgesic nephropathy and UTUCs in kidney transplant recipients (KTRs). Analgesic nephropathy is characterized by chronic renal interstitial nephritis with resultant renal functional impairment (in approximately $80 \%$ of cases) or even progression to end-stage renal disease (in approximately $10 \%$ of cases). KTRs with analgesic nephropathy have an increased risk of urothelial carcinomas (UCs), characterized by progressive upper urinary tract involvement [8]. UCs are more prevalent in female KTRs [8]. The proportion $(2.8 \%, 7 / 250)$ of UCs in KTRs with analgesic nephropathy is significantly higher than that $(0.49 \%, 7 / 1424)$ in KTRs without analgesic nephropathy [8]. In that study, all seven KTRs with UCs and analgesic nephropathy were female; moreover, they all experienced subsequent UTUCs following initial bladder involvement. In contrast, all seven KTRs with UCs and nonanalgesic nephropathy were male and, furthermore, they only had bladder UCs [8]. However, following the commercial withdrawal of compound analgesics containing phenacetin, a trend toward a decreased incidence of renal pelvic UCs has been observed [7, 9].

Aristolochic acid is a powerful nephrotoxin and human carcinogen, which also explains the association between CKD and UTUCs [10, 11]. Aristolochic acid nephropathy, first reported in Belgium, is characterized by chronic tubulointerstitial nephritis (in 93.3\% of cases), which may progress to end-stage renal disease [12-14]. A variety of Chinese herbal remedies containing aristolochic acid for weight loss and a plethora of other ailments, including menstrual symptoms, snakebites, rheumatism, arthritis, and gout (especially in females), have been proven popular in Taiwan and China, among other countries $[10,11,14]$. A recent study in 152 Taiwanese UTUC patients revealed high prevalence rates for aristolactam deoxyribonucleic acid (DNA) adducts and p53 mutations, which serve as biomarkers of aristolochic acid exposure and demonstrate a close association between aristolochic acid exposure and UTUCs [10]. Recently, Balkan endemic nephropathy has been categorized as a form of aristolochic acid nephropathy due to the identification of aristolochic acid in Aristolochia clematitis [12, 13, 15]. Balkan endemic nephropathy is associated with a 100 -fold increased frequency of UTUCs compared with nonendemic areas [16]. Consumption of contaminated or aristolochic acid containing Chinese herbal remedies or foods raises the likelihood of developing UTUCs and CKD; accordingly, banning its use has become an important global public health issue.

\section{Upper Tract Urothelial Carcinomas in Dialysis Patients: A Diagnostic Challenge}

Urothelial carcinoma (UC) is the most frequently presenting malignancy in dialysis patients in Taiwan and Balkan endemic nephropathy areas [17]. Dialysis patients also have a higher cancer risk. In dialysis and end-stage renal disease patients, DNA repair impairment, immune dysfunction, and antioxidant defense reduction, in addition to carcinogen accumulation and chronic infection or inflammation, are all potential factors for increased cancer risk [18]. Overall cancer risk in dialysis patients is $10-80 \%$ higher compared with the general population $[19,20]$. The prevalence of each type of cancer in dialysis patients varies according to geographical area. Overall, renal cell carcinoma represents the most common urinary tumor in dialysis patients in Europe, Australia, and New Zealand [21]. In contrast, UCs present with unusual frequency $(0.9-1.7 \%)$ in dialysis patients in Taiwan and Balkan endemic nephropathy areas, compared with patients in Europe, Australia, and New Zealand (0.3-0.6\%, Table 1) $[17,21-25]$. UCs in dialysis patients in Taiwan and Balkan endemic nephropathy areas are observed predominantly in females (53.8-70.6\%; median, 61.3\%) and upper tract (31.6$62.5 \%$; median, $52.9 \%$, Table 1 ). They are associated with both consumption of aristolochic acid in females and Balkan endemic nephropathy [17, 21-25]. 
TABLE 2: Detection rates for urothelial carcinomas and upper tract urothelial carcinomas in dialysis patients using urological and imaging methods.

\begin{tabular}{|c|c|c|c|c|}
\hline Patients & Test & $\begin{array}{c}\text { Positive result }(n) / \text { total } \\
\text { number }(N)\end{array}$ & Detection rate (\%) & Reference \\
\hline \multirow{8}{*}{ Urothelial carcinoma } & \multirow{2}{*}{ Urine cytology } & $7 / 24$ & $29.2 \%$ & Wang et al. [17] \\
\hline & & $2 / 6$ & $33.3 \%$ & Chen et al. [23] \\
\hline & Retrograde pyelography & $21 / 28$ & $75.0 \%$ & Wang et al. [17] \\
\hline & Cystoscopy & $67 / 80$ & $80.7 \%$ & Wang et al. [17] \\
\hline & Computed tomography & $42 / 51$ & $82.4 \%$ & Wang et al. [17] \\
\hline & Magnetic resonance imaging & $37 / 39$ & $94.9 \%$ & Wang et al. [17] \\
\hline & Cystoscopy and/or retrograde pyelography & $14 / 16$ & $87.5 \%$ & Chen et al. [23] \\
\hline & Computed tomography and endoscopy & $16 / 16$ & $100.0 \%$ & Satoh et al. [28] \\
\hline \multirow{3}{*}{$\begin{array}{l}\text { Upper tract urothelial } \\
\text { carcinoma }\end{array}$} & Urine cytology & $0 / 10$ & $0.0 \%$ & Satoh et al. [28] \\
\hline & Retrograde pyelography & $6 / 7$ & $85.7 \%$ & Chen et al. [23] \\
\hline & Computed tomography and endoscopy & $10 / 10$ & $100.0 \%$ & Satoh et al. [28] \\
\hline
\end{tabular}

$n$ : number of patients with positive results in each diagnostic test.

$N$ : number of patients who underwent each diagnostic test.

Diagnosis of UTUCs in dialysis patients represents a clinical challenge, especially in the early stages. The most commonly presenting symptom is gross hematuria, that is, "bloody urethral discharge," observed in over $90 \%$ of patients $[26,27]$. However, heparinization for dialysis also results in hematuria [25]. Hematuria in dialysis patients signals the need of further investigation but does not lead to a specific diagnosis. Invasive UTUCs in dialysis patients are associated with a reduced likelihood of survival $[26,27]$. Therefore, correct and early diagnosis of UTUCs represents an important goal.

Reported detection rates for UCs and UTUCs in dialysis patients have varied markedly across a number of urological and imaging studies (Table 2) [17, 23, 28]. Furthermore, these results provide information pertaining only to truepositive (detection rates) and false-negative rates $[17,23$, 28]. Traditionally, urine cytology, retrograde pyelography, and cystoscopy have been used to diagnose UCs in dialysis patients [26]. Urine cytology is associated with an extremely low detection rate $(0.0-33.3 \%)$ for UCs, especially UTUCs, in dialysis patients $[17,23,28]$. It is also impractical to use urine cytology to screen for UCs and UTUCs, because the majority of dialysis patients experience anuria [23]. Furthermore, although urine cytology can indicate the presence of UC, it cannot differentiate UTUCs from bladder UCs. Diagnosis of UTUCs during retrograde pyelography is primarily based on filling defects in the upper urinary tracts, with imaging characteristics suggestive of UTUCs. The detection rates for UCs and UTUCs in dialysis patients using retrograde pyelography have been reported as $75.0 \%$ and $85.7 \%$, respectively $[17,23]$. Detection rates for retrograde pyelography may be overestimated due to the exclusion of cases involving technical failure or insufficient diagnostic information. Technical failure usually refers to the inability to identify or catheterize ureteral lumen using cystoscopy, due to ureter atrophy or ureter trauma by ureter fibrosis $[29,30]$. Tumors or blood located in more distal parts of the ureter can hinder the detection of proximally located UTUCs, leading to insufficient diagnostic information pertaining to retrograde pyelography $[29,30]$. Cystoscopy has principally been used to detect bladder UCs rather than UTUCs. The majority of UTUCs are not detectable using cystoscopy, with the exception of ureteral UCs protruding into the bladder cavity via the ureteral orifice. Therefore, retrograde pyelography might be a more reliable tool for detecting UTUCs compared with urine cytology and cystoscopy. A combination of cystoscopy and retrograde pyelography might be capable of detecting the majority of bladder UCs and UTUCs in dialysis patients.

Recently, computed tomography (CT) and magnetic resonance imaging (MRI) have been proposed for use in the diagnosis and staging of UTUCs in dialysis patients [26]. The detection rates for UCs using CT and MRI have recently been reported as $82.4 \%$ and $94.9 \%$, respectively (Table 2) [17]. For dialysis patients experiencing anuria, contrastenhanced CT can be performed without the concern of contrast-induced nephropathy, because the renal functions of these patients are particularly compromised. The contrastenhancing nature of UTUCs renders them distinguishable from nonenhancing hematoma; moreover, their presence on contrast-enhanced CT is highlighted by amplified differences in density between UTUCs and surrounding normal tissue. Using unenhanced MRI, UTUCs in dialysis patients exhibit variable signal intensities, which help distinguish them from adjacent, normal structures. Similar to contrastenhanced CT, the use of a gadolinium-based contrast agent for enhanced MRI in dialysis patients would also help in the detection of UTUCs. However, three gadolinium-based contrast agents are associated with the greatest number of nephrogenic systemic fibrosis cases; thus, their application is contraindicated in dialysis patients [31]. Instead, other gadolinium-based contrast agents should be employed if there is a strong clinical need for enhanced MRI. In summary, CT and MRI could be valuable tools for detecting UTUCs 
in dialysis patients. However, large-scale studies focusing on the diagnostic accuracy of CT and MRI are necessary to corroborate their efficacy.

Detection of recurrent UCs in dialysis patients with initial UTUCs during follow-up is very important if prophylactic total urinary tract extirpation has not been performed [27]. Recurrence of contralateral UTUCs and bladder UCs in dialysis patients with UTUCs is very common, occurring in $31.1-37.9 \%$ and $52.6 \%$ of patients, respectively $[26,27,32]$. To completely eliminate the need to detect recurrence, $\mathrm{Wu}$ et al. suggested the performance of total urinary tract extirpation during one-stage surgery in the treatment of dialysis patients with UTUCs. However, higher perioperative mortality rates are observed in dialysis patients with cystectomy, compared with dialysis patients without cystectomy [27]. For dialysis patients with UTUCs and preserved urinary bladders, a regular cystoscopy, every 3 months for the first 2 years and annually thereafter, has been suggested for the detection of recurrence in the urinary bladder [27]. For dialysis patients with initially unilateral UTUCs who have undergone unilateral nephroureterectomy only, enhanced CT or MRI might represent a useful, noninvasive means of detecting recurrence in the contralateral upper urinary tract.

\section{Upper Tract Urothelial Carcinomas in Kidney Transplant Recipients: A Diagnostic Challenge}

The incidence of UCs in KTRs varies by geographic area. In China and Taiwan, the proportion of UCs in KTRs is unusually high: $0.9-4.1 \%$ versus $0.1-1.1 \%$ in other regions (Table 3) [33-51]. Impaired immunity due to immunosuppressants, viral infection, and uremia has been proposed as a risk factor for the development of malignancies in KTRs [35], which have a malignancy incidence rate approximately 4-5fold higher than that for the general population $[35,50,52]$. In the majority of areas, the most frequent malignant tumors in KTRs are lymphomas, followed by skin cancer [35]. However, in KTRs in Taiwan and China, UCs are the most common presenting malignancy, predominantly in females (58.381.0\%; median, 70.6\%) [33-42]. A high proportion (40.793.3\%; median, $80.7 \%$ ) of native UTUCs and the involvement of multifocal sites (i.e., $\geqq$ two organs of the urinary tract) are also observed (Table 3) [33-42]. Early recurrence in the urinary bladder or contralateral upper urinary tract is also common in UCs in KTRs in China and Taiwan [33-42]. These features of UCs in KTRs in China and Taiwan are quite different from those of the predominant bladder UCs and from the male predominance of UCs observed for KTRs in other areas [33-51].

The prognosis of KTRs with UTUCs depends primarily on the tumor stage and tumor grade [37, 38]. However, it is difficult to diagnose UCs in KTRs at an early stage, especially UTUCs of the native upper urinary tract, according to clinical symptoms alone [35]. Invasive UTUCs are often characterized by progressive multifocal recurrence, even following adjunctive radiotherapy or systemic chemotherapy, and patients may ultimately die due to metastasis $[46,47]$. In contrast, noninvasive UTUCs are associated with low recurrence and mortality rates $[46,47]$. UCs in KTRs present with a wide variety of symtoms or are sometimes asymptomatic [37-40, 51, 53]. Painless gross hematuria represents the most common symptom, followed by microscopic hematuria and chronic urinary tract infection $[37-40,51,53]$. Occasionally, KTRs with UCs present with fever, urinary retention, weight loss, or bone pain [51, 53]. Unfortunately, these clinical symptoms are nonspecific to UCs and UTUCs [37-40, 51, 53]. Other urinary diseases and even healthy KTRs can also present with these symptoms [37-40, 51, 53]. Furthermore, asymptomatic KTRs with UCs account for $11.4-45.5 \%$ of cases $[37,51,53]$. Therefore, diagnosis of UTUCs in KTRs according to the clinical symptoms often leads to delayed diagnoses [35-37, 40].

A variety of urological and imaging methods have been employed traditionally in the diagnosis of UCs and UTUCs in KTRs, but they are all characterized by certain shortcomings [35-37, 40, 51, 53]. The detection rates for UCs and UTUCs in KTRs using these methods are provided in Table 4 [35$37,40,51,53]$. Urine cytology collected from spontaneously voided urine is associated with a wide range of detection rates (8.3-81.5\%; median, 47\%) for UCs in KTRs [35-37, 40, 51, 53]. The reported low detection rate for UCs in KTRs using urine cytology could be explained by poor functioning of the native upper urinary tracts $[35,40,53]$. Renal ultrasound of native kidneys usually reveals secondary hydronephrosis rather than UTUCs themselves, which is particularly facilitative for the diagnosis of UTUCs in asymptomatic patients [36, 37, 40, 51, 53]. Renal ultrasound alone, however, detected only $9.1-53.6 \%$ of UTUCs in KTRs [36, 37, 40, 51, 53]; accordingly, it usually serves as a complementary tool only in the detection of native UTUCs. Cystoscopic and ureteroscopic biopsy detected 38\% and 50\% of UCs in KTRs, respectively [35]. However, ureteroscopy confers a risk of native upper urinary tract rupture due to inherent poor elasticity [53]. The invasive nature of cystoscopy and ureteroscopy renders them unsuitable routine screening tools for UCs and UTUCs in KTRs; they are typically used to confirm the presence of UCs in symptomatic KTRs [29, 40]. In summary, the use of a single traditional method alone is likely to underestimate UC and UTUC occurrence in KTRs. Urine cytology combined with abdominal ultrasound has been used to screen for UCs in KTRs but detected only onethird of UCs; moreover, these UCs were advanced, and the mortality rate was commensurately high [53]. In contrast, a detection rate of $96.7 \%$, for UCs in KTRs using a combination of cystoscopy and retrograde pyelography, has been reported [40]. This approach is justified in clinically suspected patients, but its feasibility for the screening of UCs in KTRs remains contentious due to its invasiveness.

With advancements in imaging technology, CT urography is now a promising tool for the detection of UTUCs in KTRs. CT urography has high specificity (93-99\%) and moderate-to-high sensitivity (67-100\%) in hematuria patients with sufficient renal function [30, 54-61]. CT urography is also more accurate than excretory urography for diagnosing UTUCs in these patients $[56,61]$. Therefore, CT urography has been recommended as a first-line imaging tool 
TABLE 3: Proportions, locations, and gender distribution of UCs and UTUCs in kidney transplant recipients.

\begin{tabular}{|c|c|c|c|c|c|}
\hline \multirow{2}{*}{ Reference (country) } & \multicolumn{2}{|c|}{ Proportion in kidney transplant recipients } & \multicolumn{3}{|c|}{ Proportion in kidney transplant recipients with urothelial carcinomas } \\
\hline & $\begin{array}{l}\text { Kidney transplant } \\
\text { recipients }(n)\end{array}$ & $\begin{array}{c}\text { Urothelial } \\
\text { carcinoma (\%) }\end{array}$ & Female (\%) & Multifocal (\%) & $\begin{array}{c}\text { Upper tract urothelial } \\
\text { carcinoma }(\%)\end{array}$ \\
\hline $\begin{array}{l}\text { Einollahi et al. [44] } \\
\text { (Iran) }\end{array}$ & 5532 & $\begin{array}{c}7 \\
(0.1 \%)\end{array}$ & $\begin{array}{c}2 \\
(28.6 \%)\end{array}$ & $\begin{array}{c}0 \\
(0.0 \%)\end{array}$ & $\begin{array}{c}0 \\
(0.0 \%)\end{array}$ \\
\hline $\begin{array}{l}\text { Hoshida et al. [47] } \\
\text { (Japan) }\end{array}$ & 1744 & $\begin{array}{c}2 \\
(0.1 \%)\end{array}$ & $\begin{array}{c}0 \\
(0.0 \%)\end{array}$ & $\begin{array}{c}0 \\
(0.0 \%)\end{array}$ & $\begin{array}{c}0 \\
(0.0 \%)\end{array}$ \\
\hline $\begin{array}{l}\text { Cox and Colli [43] } \\
\text { (USA) }\end{array}$ & 5920 & $\begin{array}{c}11 \\
(0.2 \%)\end{array}$ & $\begin{array}{c}2 \\
(18.2 \%)\end{array}$ & $\begin{array}{c}0 \\
(0.0 \%)\end{array}$ & $\begin{array}{c}1 \\
(9.1 \%)\end{array}$ \\
\hline $\begin{array}{l}\text { Elkentaoui et al. [45] } \\
\text { (France) }\end{array}$ & 1350 & $\begin{array}{c}5 \\
(0.4 \%)\end{array}$ & $\begin{array}{c}0 \\
(0.0 \%)\end{array}$ & $\begin{array}{c}0 \\
(0.0 \%)\end{array}$ & $\begin{array}{c}0 \\
(0.0 \%)\end{array}$ \\
\hline $\begin{array}{l}\text { Karczewski et al. [48] } \\
\text { (Poland) }\end{array}$ & 836 & $\begin{array}{c}3 \\
(0.4 \%)\end{array}$ & $\begin{array}{c}1 \\
(33.3 \%)\end{array}$ & $\begin{array}{c}0 \\
(0.0 \%)\end{array}$ & $\begin{array}{c}0 \\
(0.0 \%)\end{array}$ \\
\hline $\begin{array}{l}\text { Rogers et al. [50] } \\
\text { (UK) }\end{array}$ & 1647 & $\begin{array}{c}8 \\
(0.5 \%)\end{array}$ & NA & $\begin{array}{c}0 \\
(0.0 \%)\end{array}$ & $\begin{array}{c}0 \\
(0.0 \%)\end{array}$ \\
\hline Gaya et al. [46] (UK) & 274 & $\begin{array}{c}3 \\
(1.1 \%)\end{array}$ & NA & $\begin{array}{c}0 \\
(0.0 \%)\end{array}$ & $\begin{array}{c}0 \\
(0.0 \%)\end{array}$ \\
\hline $\begin{array}{l}\text { Melchior et al. [49] } \\
\text { (Germany) }\end{array}$ & 802 & $\begin{array}{c}8 \\
(1.0 \%)\end{array}$ & NA & $\begin{array}{c}0 \\
(0.0 \%)\end{array}$ & $\begin{array}{c}2 \\
(25.0 \%)\end{array}$ \\
\hline $\begin{array}{l}\text { Tsaur et al. [51] } \\
\text { (Germany) }\end{array}$ & 2001 & $\begin{array}{c}21 \\
(1.1 \%)\end{array}$ & $\begin{array}{c}12 \\
(57.1 \%)\end{array}$ & $\begin{array}{c}4 \\
(19.1 \%)\end{array}$ & $\begin{array}{c}6 \\
(28.6 \%)\end{array}$ \\
\hline Liu et al. [38] (China) & 2572 & $\begin{array}{c}24 \\
(0.9 \%)\end{array}$ & $\begin{array}{c}14 \\
(58.3 \%)\end{array}$ & $\begin{array}{c}15 \\
(62.5 \%)\end{array}$ & $\begin{array}{c}21 \\
(87.5 \%)\end{array}$ \\
\hline Hao et al. [33] (China) & 1945 & $\begin{array}{c}19 \\
(1.0 \%)\end{array}$ & NA & $\begin{array}{c}7 \\
(36.8 \%)\end{array}$ & $\begin{array}{c}15 \\
(79.0 \%)\end{array}$ \\
\hline Hu et al. [34] (China) & 1293 & $\begin{array}{c}21 \\
(1.6 \%)\end{array}$ & $\begin{array}{c}17 \\
(81.0 \%)\end{array}$ & $\begin{array}{c}9 \\
(42.9 \%)\end{array}$ & $\begin{array}{c}15 \\
(71.4 \%)\end{array}$ \\
\hline Li et al. [36] (China) & 1429 & $\begin{array}{c}27 \\
(1.9 \%)\end{array}$ & $\begin{array}{c}21 \\
(77.8 \%)\end{array}$ & $\begin{array}{c}3 \\
(11.1 \%)\end{array}$ & $\begin{array}{c}11 \\
(40.7 \%)\end{array}$ \\
\hline $\begin{array}{l}\text { Xiao et al. [41] } \\
\text { (China) }\end{array}$ & 3790 & $\begin{array}{c}100 \\
(2.6 \%)\end{array}$ & NA & $\begin{array}{c}53 \\
(58.9 \%)^{*}\end{array}$ & $\begin{array}{c}68 \\
(75.6 \%)\end{array}$ \\
\hline $\begin{array}{l}\text { Liao et al. [37] } \\
\text { (Taiwan) }\end{array}$ & 663 & $\begin{array}{c}17 \\
(2.6 \%)\end{array}$ & NA & $\begin{array}{c}11 \\
(64.7 \%)\end{array}$ & $\begin{array}{c}14 \\
(82.4 \%)\end{array}$ \\
\hline $\begin{array}{l}\text { Wang et al. [39] } \\
\text { (Taiwan) }\end{array}$ & 320 & $\begin{array}{c}10 \\
(3.1 \%)\end{array}$ & $\begin{array}{c}8 \\
(80.0 \%)\end{array}$ & $\begin{array}{c}4 \\
(40.0 \%)\end{array}$ & $\begin{array}{c}6 \\
(60.0 \%)\end{array}$ \\
\hline $\begin{array}{l}\text { Zhang et al. [42] } \\
\text { (China) }\end{array}$ & 3462 & $\begin{array}{c}112 \\
(3.2 \%)\end{array}$ & NA & $\begin{array}{c}69 \\
(61.6 \%)\end{array}$ & $\begin{array}{c}93 \\
(83.0 \%)\end{array}$ \\
\hline $\begin{array}{l}\text { Kao et al. [35] } \\
\text { (Taiwan) }\end{array}$ & 670 & $\begin{array}{c}24 \\
(3.6 \%)\end{array}$ & $\begin{array}{c}15 \\
(62.5 \%)\end{array}$ & $\begin{array}{c}19 \\
(79.2 \%)\end{array}$ & $\begin{array}{c}21 \\
(87.5 \%)\end{array}$ \\
\hline $\begin{array}{l}\text { Wu et al. [40] } \\
\text { (Taiwan) }\end{array}$ & 730 & $\begin{array}{c}30 \\
(4.1 \%)\end{array}$ & $\begin{array}{c}19 \\
(63.3 \%)\end{array}$ & $\begin{array}{c}23 \\
(76.7 \%)\end{array}$ & $\begin{array}{c}28 \\
(93.3 \%)\end{array}$ \\
\hline
\end{tabular}

NA: not available.

* Based on 90 UC patients meeting the inclusion criteria of pathological samples.

for diagnosing UTUCs, due to its high accuracy and noninvasive nature $[58,62]$. Does CT urography display similar results for the detection of UTUCs in KTRs? The detection rate has been reported as $85.7 \%$ (Table 4) [63], lower than that $(95.8 \%)$ seen in hematuria patients (non-KTRs) [61, 63] but nonetheless probably higher than those associated with other more traditional methods. Smaller UTUC sizes and poor contrast opacification of native upper urinary tract in KTRs may explain the lower detection rate of CT urography in KTRs. Two novel indicators of native ureteral UCs in KTRs have been identified using CT urography [63]; the fork sign (Figure 1) indicates ureteral UCs with proximal dilatation
[64]. Conversely, the spindle sign (Figure 2) is indicative of ureteral UCs in nondilated native ureters, which deform the corresponding ureteral segment into spindle shapes [64]. Additional CT urography studies employing large numbers of KTRs are necessary to corroborate its efficacy in the detection of UTUCs.

A pretransplantation survey of the urinary tract using cystoscopy, CT urography, renal ultrasound, and urine cytology should be conducted to exclude the presence of UC in renal transplantation candidates. The shortest interval between subsequent UC diagnosis following renal transplantation has been reported to be 2 months, suggesting that 
TABLE 4: Detection rates of urothelial carcinomas and upper tract urothelial carcinomas in kidney transplant recipients using urological and imaging methods.

\begin{tabular}{|c|c|c|c|c|}
\hline Patients & Test & $\begin{array}{c}\text { Positive result }(n) / \text { total } \\
\text { number }(N)\end{array}$ & Detection rate $(\%)$ & Reference \\
\hline \multirow{10}{*}{ Urothelial carcinoma } & \multirow{6}{*}{ Urine cytology } & $2 / 24$ & $8.3 \%$ & Kao et al. [35] \\
\hline & & $7 / 30$ & $23.3 \%$ & Wu et al. [40] \\
\hline & & $3 / 11$ & $27.3 \%$ & Kliem et al. [53] \\
\hline & & $24 / 21$ & $66.7 \%$ & Tsaur et al. [51] \\
\hline & & $12 / 16$ & $75.0 \%$ & Liao et al. [37] \\
\hline & & $22 / 27$ & $81.5 \%$ & Li et al. [36] \\
\hline & Cystoscopic biopsy & $9 / 24$ & $37.5 \%$ & Kao et al. [35] \\
\hline & Ureteroscopic biopsy & $12 / 24$ & $50.0 \%$ & Kao et al. [35] \\
\hline & Urine cytology and abdominal ultrasound & $4 / 11$ & $36.3 \%$ & Kliem et al. [53] \\
\hline & Cystoscopy and retrograde pyelography & $29 / 30$ & $96.7 \%$ & Wu et al. [40] \\
\hline \multirow{6}{*}{$\begin{array}{l}\text { Upper tract urothelial } \\
\text { carcinoma }\end{array}$} & \multirow{5}{*}{ Native kidney ultrasound } & $1 / 11$ & $9.1 \%$ & Li et al. [36] \\
\hline & & $1 / 6$ & $16.7 \%$ & Tsaur et al. [51] \\
\hline & & $2 / 14$ & $14.4 \%$ & Liao et al. [37] \\
\hline & & $2 / 6$ & $33.3 \%$ & Kliem et al. [53] \\
\hline & & $15 / 28$ & $53.6 \%$ & Wu et al. [40] \\
\hline & CT urography & $12 / 14$ & $85.7 \%$ & Wang et al. [63] \\
\hline
\end{tabular}

$n$ : number of patients with positive results in each diagnostic test.

$N$ : number of patients who underwent each diagnostic test.

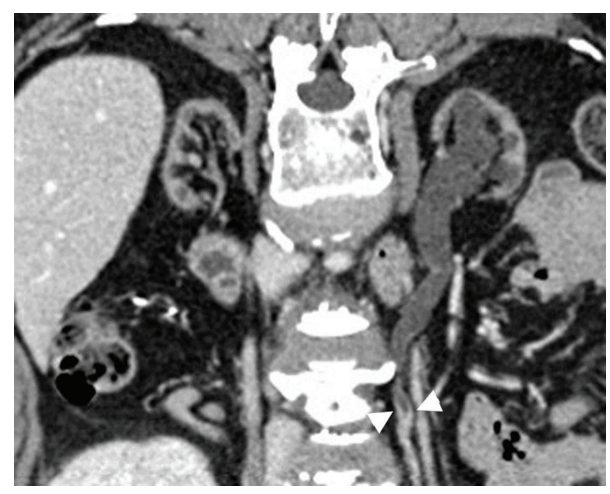

FIGURE 1: Curved planar reformatted image of computed tomography urography of a 56-year-old female kidney transplant recipient exhibits a fork sign (arrowheads) in the left native ureter representing a left ureteral UC.

these UCs probably existed prior to renal transplantation $[35,37,38]$. KTRs with preexisting UTUCs may have a poor prognosis, with early tumor dissemination to lymph nodes and distant organs despite aggressive treatment using bilateral nephroureterectomy [37]. Therefore, by undergoing a standard pretransplantation urological and imaging survey, the risk of preexisting UCs in KTRs could be reduced. Furthermore, the results of standard pretransplantation surveys could serve as a baseline to highlight any interval changes following renal transplantation.

\section{Conclusion}

CKD and UTUC share a bidirectional association. Analgesics and aristolochic acid are common risk factors for CKD and

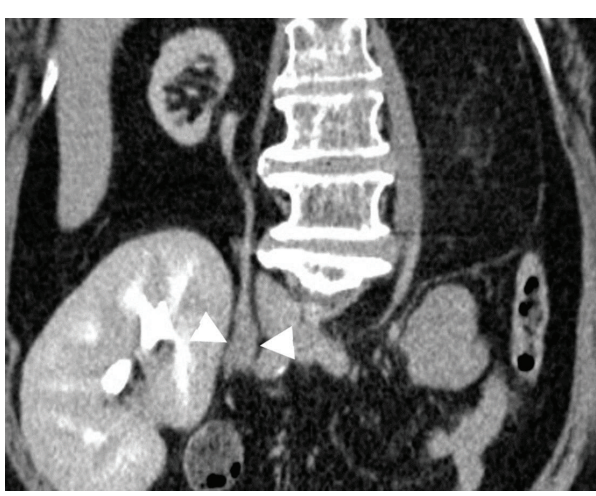

FIGURE 2: Curved planar reformatted image of computed tomography urography of a 55-year-old female kidney transplant recipient exhibits a spindle sign in the right native ureter (arrowheads) indicative of urothelial carcinoma.

UTUCs due to their nephrotoxic and carcinogenic effects. The ban on aristolochic acid containing medicines and foods to decrease aristolochic acid nephropathy and associated UTUCs has become an important global public health issue. Early and correct diagnosis of UTUCs in dialysis patients and KTRs is important but difficult. Urine cytology and cystoscopy have limited sensitivity for the diagnosis of UTUCs in dialysis patients. Enhanced CT and MRI could prove useful for the detection and staging of UTUCs in dialysis patients. Renal ultrasound is useful to detect hydronephrosis in KTRs with asymptomatic UTUCs; however, hydronephrosis is not specific to UTUCs. CT urography represents a promising tool to detect UTUCs in KTRs due to its high detection rate. Prior to renal transplantation, a urinary tract survey should be performed for the early detection of preexisting UTUCs. Regular screening of asymptomatic patients and diagnostic 
work-up for symptomatic patients using a combination of urological and imaging methods should be performed to achieve early diagnosis of UTUCs in dialysis patients and KTRs. Careful assessment of subsequent recurrence within the contralateral upper tract and the urinary bladder is essential in dialysis patients and KTRs with UTUCs.

\section{Conflict of Interests}

The authors declare that there is no conflict of interests regarding the publication of this paper.

\section{Acknowledgment}

The authors thank Chung-Yi Liu M.D. for his input in their scientific discussions.

\section{References}

[1] F. National Kidney, "K/DOQI clinical practice guidelines for chronic kidney disease: evaluation, classification, and stratification," American Journal of Kidney Diseases, vol. 39, p. S1, 2002.

[2] A. S. Levey, K. U. Eckardt, Y. Tsukamoto et al., "Definition and classification of chronic kidney disease: a position statement from Kidney Disease: improving Global Outcomes (KDIGO)," Kidney International, vol. 67, no. 6, pp. 2089-2100, 2005.

[3] G. Xiong, X. Chen, X. Li et al., "Prevalence and factors associated with baseline chronic kidney disease in China: a 10-year study of 785 upper urinary tract urothelial carcinoma patients," Journal of the Formosan Medical Association, vol. 113, no. 8, pp. 521-526, 2014.

[4] C. Y. Chen, Y. M. Liao, W. M. Tsai, and H. Kuo, "Upper urinary tract urothelial carcinoma in eastern Taiwan: high proportion among all urothelial carcinomas and correlation with chronic kidney disease," Journal of the Formosan Medical Association, vol. 106, no. 12, pp. 992-998, 2007.

[5] M. Fernandez Lucas, J. Burgos, C. Quereda et al., "Dialysis in patients with bilateral nephrectomy for transitional cell carcinoma," Nephron, vol. 69, no. 1, pp. 112-113, 1995.

[6] P. H. Hung, C. H. Shen, Y. L. Chiu et al., "The aggressiveness of urinary tract urothelial carcinoma increases with the severity of chronic kidney disease," BJU International, vol. 104, no. 10, pp. 1471-1474, 2009.

[7] B. Stengel, "Chronic kidney disease and cancer: a troubling connection," Journal of Nephrology, vol. 23, no. 3, pp. 253-262, 2010.

[8] P. Swindle, M. Falk, R. Rigby, J. Petrie, C. Hawley, and D. Nicol, "Transitional cell carcinoma in renal transplant recipients: the influence of compound analgesics," British Journal of Urology, vol. 81, no. 2, pp. 229-233, 1998.

[9] M. McCredie, J. H. Stewart, T. H. Mathew, A. P. S. Disney, and J. M. Ford, "The effect of withdrawal of phenacetin-containing analgesics on the incidence of kidney and urothelial cancer and renal failure," Clinical Nephrology, vol. 31, no. 1, pp. 35-39, 1989.

[10] C. Chen, K. G. Dickman, C. Huang et al., "Aristolochic acidinduced upper tract urothelial carcinoma in Taiwan: clinical characteristics and outcomes," International Journal of Cancer, vol. 133, no. 1, pp. 14-20, 2013.
[11] J. L. Nortier, M. M. Martinez, H. H. Schmeiser et al., "Urothelial carcinoma associated with the use of a Chinese herb (Aristolochia fangchi)," The New England Journal of Medicine, vol. 342, no. 23, pp. 1686-1692, 2000.

[12] V. Jha, G. Garcia-Garcia, K. Iseki et al., "Chronic kidney disease: global dimension and perspectives," The Lancet, vol. 382, no. 9888, pp. 260-272, 2013.

[13] V. Stefanovic, R. Cukuranovic, S. Miljkovic, D. Marinkovic, and D. Toncheva, "Fifty years of balkan endemic nephropathy: challenges of study using epidemiological method," Renal Failure, vol. 31, no. 5, pp. 409-418, 2009.

[14] J. L. Vanherweghem, M. Depierreux, C. Tielemans et al., "Rapidly progressive interstitial renal fibrosis in young women: association with slimming regimen including Chinese herbs," The Lancet, vol. 341, no. 8842, pp. 387-391, 1993.

[15] A. P. Grollman and B. Jelaković, "Role of environmental toxins in endemic (Balkan) nephropathy. October 2006, Zagreb, Croatia," Journal of the American Society of Nephrology, vol. 18, no. 11, pp. 2817-2823, 2007.

[16] V. Stefanovic, M. Polenakovic, and D. Toncheva, "Urothelial carcinoma associated with Balkan endemic nephropathy. A worldwide disease," Pathologie Biologie, vol. 59, no. 5, pp. 286291, 2011.

[17] T. Wang, C. Hu, C. Kuo et al., "High incidence and recurrence of transitional cell carcinoma in Taiwanese patients with end-stage renal disease," Nephrology, vol. 16, no. 2, pp. 225-231, 2011.

[18] H. F. Lin, Y. H. Li, C. H. Wang, C. L. Chou, D. J. Kuo, and T. C. Fang, "Increased risk of cancer in chronic dialysis patients: a population-based cohort study in Taiwan," Nephrology Dialysis Transplantation, vol. 27, no. 4, pp. 1585-1590, 2012.

[19] P. Maisonneuve, L. Agodoa, R. Gellert et al., "Cancer in patients on dialysis for end-stage renal disease: an international collaborative study," The Lancet, vol. 354, no. 9173, pp. 93-99, 1999.

[20] C. M. Vajdic, S. P. McDonald, M. R. E. McCredie et al., "Cancer incidence before and after kidney transplantation," Journal of the American Medical Association, vol. 296, no. 23, pp. 28232831, 2006

[21] J. H. Stewart, G. Buccianti, L. Agodoa et al., "Cancers of the kidney and urinary tract in patients on dialysis for end-stage renal disease: analysis of data from the United States, Europe, and Australia and New Zealand," Journal of the American Society of Nephrology, vol. 14, no. 1, pp. 197-207, 2003.

[22] C. Chang, C. Yang, and A. Yang, "Renal diagnosis of chronic hemodialysis patients with urinary tract transitional cell carcinoma in Taiwan," Cancer, vol. 109, no. 8, pp. 1487-1492, 2007.

[23] K. S. Chen, M. K. Lai, C. C. Huang, S. Chu, and M. L. Leu, "Urologic cancers in uremic patients," American Journal of Kidney Diseases, vol. 25, no. 5, pp. 694-700, 1995.

[24] C. Cuckovic, L. Djukanovic, S. Jankovic et al., "Malignant tumors in hemodialysis patients," Nephron, vol. 73, no. 4, pp. 710-712, 1996.

[25] J. H. Ou, C. C. Pan, J. S. Lin et al., “Transitional cell carcinoma in dialysis patients," European Urology, vol. 37, p. 90, 2000.

[26] C. F. Wu, P. L. Chang, C. S. Chen, C. Chuang, H. Weng, and S. Pang, "The outcome of patients on dialysis with upper urinary tract transitional cell carcinoma," Journal of Urology, vol. 176, no. 2, pp. 477-481, 2006.

[27] C. H. Kang, C. H. Chen, and P. H. Chiang, "Primary urothelial carcinoma of the upper urinary tract in dialysis patients with 5-year follow-up," Japanese Journal of Clinical Oncology, vol. 40, no. 3, Article ID hyp143, pp. 241-246, 2009. 
[28] S. Satoh, N. Tsuchiya, T. Habuchi, T. Ishiyama, K. Seimo, and T. Kato, "Renal cell and transitional cell carcinoma in a Japanese population undergoing maintenance dialysis," Journal of Urology, vol. 174, no. 5, pp. 1749-1753, 2005.

[29] K. S. Lee, E. Zeikus, W. C. DeWolf, N. M. Rofsky, and I. Pedrosa, "MR urography versus retrograde pyelography/ureteroscopy for the exclusion of upper urinary tract malignancy," Clinical Radiology, vol. 65, no. 3, pp. 185-192, 2010.

[30] N. C. Cowan, B. W. Turney, N. J. Taylor, C. L. McCarthy, and J. P. Crew, "Multidetector computed tomography urography for diagnosing upper urinary tract urothelial tumour," BJU International, vol. 99, no. 6, pp. 1363-1370, 2007.

[31] ACR Committee on Drugs and Contrast Media, "Neprogenic systemic fibrosis," in ACR Manual on Contrast Media, pp. 8190, 9th edition, 2013.

[32] C. H. Kang, T. J. Yu, H. H. Hsieh et al., "The development of bladder tumors and contralateral upper urinary tract tumors after primary transitional cell carcinoma of the upper urinary tract," Cancer, vol. 98, no. 8, pp. 1620-1626, 2003.

[33] J. W. Hao, H. Song, C. S. Lin et al., "Analysis of 22 cases of urological de novo malignant tumor in kidney transplant recipients," Chinese Journal of Organ Transplantation, vol. 32, p. 735, 2011.

[34] X. P. Hu, L. L. Ma, X. D. Zhang et al., "Clinical analysis of urothelial carcinoma following renal transplantation," Chinese Journal of Urology, vol. 27, p. 493, 2006.

[35] Y. Kao, Y. Ou, C. Yang, H. Ho, C. Su, and K. Shu, "Transitional cell carcinoma in renal transplant recipients," World Journal of Surgery, vol. 27, no. 8, pp. 912-916, 2003.

[36] X. B. Li, N. Z. Xing, Y. Wang, X. Hu, H. Yin, and X. Zhang, "Transitional cell carcinoma in renal transplant recipients: a single center experience," International Journal of Urology, vol. 15, no. 1, pp. 53-57, 2008.

[37] C.-H. Liao, S.-C. Chueh, M.-K. Lai, and J. Chen, "Transitional cell carcinoma in renal transplant recipients," Transplantation Proceedings, vol. 36, no. 7, pp. 2152-2153, 2004.

[38] G. M. Liu, Q. Fang, H. S. Ma, G. Sun, and X. C. Wang, "Distinguishing characteristics of urothelial carcinoma in kidney transplant recipients between China and Western countries," Transplantation Proceedings, vol. 45, no. 6, pp. 2197-2202, 2013.

[39] H. Wang, H. Hsieh, Y. Chen, C. Chiang, and Y. Cheng, "The outcome of post-transplant transitional cell carcinoma in 10 renal transplant recipients," Clinical Transplantation, vol. 16, no. 6, pp. 410-413, 2002.

[40] M. J. Wu, J. D. Lian, C. R. Yang et al., "High cumulative incidence of urinary tract transitional cell carcinoma after kidney transplantation in Taiwan," American Journal of Kidney Diseases, vol. 43, no. 6, pp. 1091-1097, 2004.

[41] J. Xiao, X. Zhu, G. Y. Hao et al., "Association between urothelial carcinoma after kidney transplantation and aristolochic acid exposure: the potential role of aristolochic acid in HRas and TP53 gene mutations," Transplantation Proceedings, vol. 43, no. 10, pp. 3751-3754, 2011.

[42] J. Zhang, L. Ma, Z. Xie et al., "Epidemiology of post-transplant malignancy in Chinese renal transplant recipients: a singlecenter experience and literature review," Medical Oncology, vol. 31, p. 32, 2014.

[43] J. Cox and J. L. Colli, "Urothelial cancers after renal transplantation," International Urology and Nephrology, vol. 43, no. 3, pp. 681-686, 2011.
[44] B. Einollahi, N. Simforoosh, M. Lessan-Pezeshki et al., "Genitourinary tumor following kidney transplantation: a multicenter study," Transplantation Proceedings, vol. 41, no. 7, pp. 28482849, 2009.

[45] H. Elkentaoui, G. Robert, G. Pasticier et al., "Therapeutic management of de novo urological malignancy in renal transplant recipients: the experience of the French Department of Urology and Kidney Transplantation from Bordeaux," Urology, vol. 75, no. 1, pp. 126-132, 2010.

[46] S. B. M. Gaya, A. J. Rees, R. I. Lechler, G. Williams, and P. D. Mason, "Malignant disease in patients with long-term renal transplants," Transplantation, vol. 59, no. 12, pp. 1705-1709, 1995.

[47] Y. Hoshida, H. Tsukuma, Y. Yasunaga et al., "Cancer risk after renal transplantation in Japan," International Journal of Cancer, vol. 71, pp. 517-520, 1997.

[48] M. Karczewski, W. Czapiewski, and J. Karczewski, "Urologic de novo malignancies after kidney transplantation: a single center experience," Transplantation Proceedings, vol. 44, no. 5, pp. 1293-1297, 2012.

[49] S. Melchior, L. Franzaring, A. Shardan et al., "Urological de novo malignancy after kidney transplantation: a case for the urologist," The Journal of Urology, vol. 185, no. 2, pp. 428-432, 2011.

[50] A. Rogers, J. K. Ng, J. Glendinning, and D. Rix, "The management of transitional cell carcinoma (TCC) in a European regional renal transplant population," BJU International, vol. 110, pp. E34-E40, 2012.

[51] I. Tsaur, A. Karalis, R. Blaheta et al., "Transitional cell carcinoma of the native urinary tract after kidney transplantation: recommendations following a long-term retrospective analysis," The American Journal of the Medical Sciences, vol. 341, no. 6, pp. 478483, 2011.

[52] Y.-M. Hung, K.-J. Chou, S.-Y. Hung, H.-M. Chung, and J.-C. Chang, "De novo malignancies after kidney transplantation," Urology, vol. 69, no. 6, pp. 1041-1044, 2007.

[53] V. Kliem, W. Thon, S. Krautzig et al., "High mortality from urothelial carcinoma despite regular tumor screening in patients with analgesic nephropathy after renal transplantation," Transplant International, vol. 9, no. 3, pp. 231-235, 1996.

[54] L. C. Chow, S. W. Kwan, E. W. Olcott, and G. Sommer, "Splitbolus MDCT urography with synchronous nephrographic and excretory phase enhancement," American Journal of Roentgenology, vol. 189, no. 2, pp. 314-322, 2007.

[55] G. A. Fritz, H. Schoellnast, H. A. Deutschmann, F. Quehenberger, and M. Tillich, "Multiphasic multidetector-row CT (MDCT) in detection and staging of transitional cell carcinomas of the upper urinary tract," European Radiology, vol. 16, no. 6, pp. 1244-1252, 2006.

[56] M. Jinzaki, K. Matsumoto, E. Kikuchi et al., "Comparison of CT urography and excretory urography in the detection and localization of urothelial carcinoma of the upper urinary tract," American Journal of Roentgenology, vol. 196, no. 5, pp. 1102-1109, 2011.

[57] E. Maheshwari, M. E. O’Malley, S. Ghai, M. Staunton, and C. Massey, "Split-bolus MDCT urography: upper tract opacification and performance for upper tract tumors in patients with hematuria," American Journal of Roentgenology, vol. 194, no. 2, pp. 453-458, 2010.

[58] M. Roupret, M. Babjuk, E. Comperat et al., "European guidelines on upper tract urothelial carcinomas: 2013 update," European Urology, vol. 63, no. 6, pp. 1059-1071, 2013. 
[59] G. S. Sudakoff, D. P. Dunn, M. L. Guralnick, R. S. Hellman, D. Eastwood, and W. A. See, "Multidetector computerized tomography urography as the primary imaging modality for detecting urinary tract neoplasms in patients with asymptomatic hematuria," The Journal of Urology, vol. 179, no. 3, pp. 862-867, 2008.

[60] L. J. Wang, Y. C. Wong, C. K. Chuang, C. Huang, and S. Pang, "Diagnostic accuracy of transitional cell carcinoma on multidetector computerized tomography urography in patients with gross hematuria," Journal of Urology, vol. 181, no. 2, pp. 524531, 2009.

[61] L. Wang, Y. Wong, C. Huang, C. Wu, S. Hung, and H. Chen, "Multidetector computerized tomography urography is more accurate than excretory urography for diagnosing transitional cell carcinoma of the upper urinary tract in adults with hematuria," The Journal of Urology, vol. 183, no. 1, pp. 48-55, 2010.

[62] M. Rouprêt, R. Zigeuner, J. Palou et al., "European guidelines for the diagnosis and management of upper urinary tract urothelial cell carcinomas: 2011 update," European Urology, vol. 59, no. 4, pp. 584-594, 2011.

[63] L. J. Wang, Y. C. Wong, and C. C. Huang, "Imaging findings of urothelial carcinomas of the upper urinary tract on multidetector computed tomography urography in kidney-transplant patients," in Proceedings of the 13th Asian Oceanian Congress of Radiology, p. 485, Taipei, Taiwan, 2010.

[64] L.-J. Wang, Y.-C. Wong, and C.-C. Huang, "Urothelial carcinoma of the native ureter in a kidney transplant recipient," The Journal of Urology, vol. 184, no. 2, p. 728, 2010. 


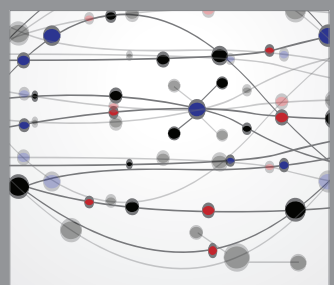

The Scientific World Journal
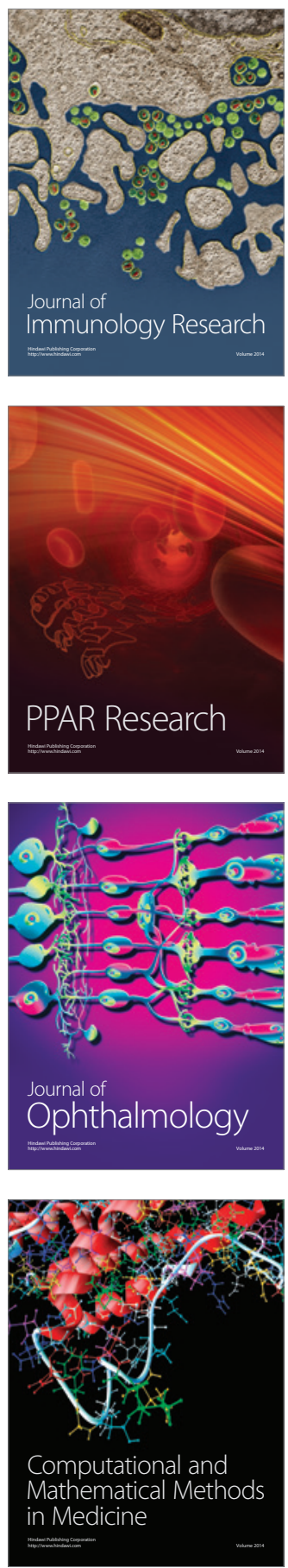

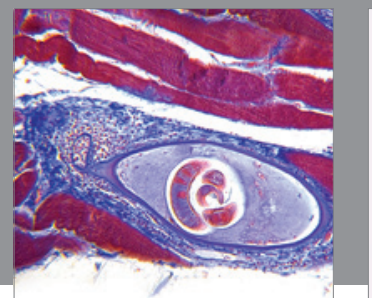

Gastroenterology

Research and Practice
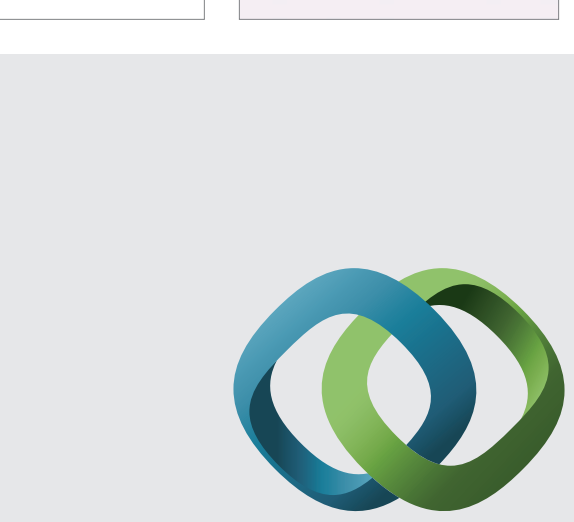

\section{Hindawi}

Submit your manuscripts at

http://www.hindawi.com
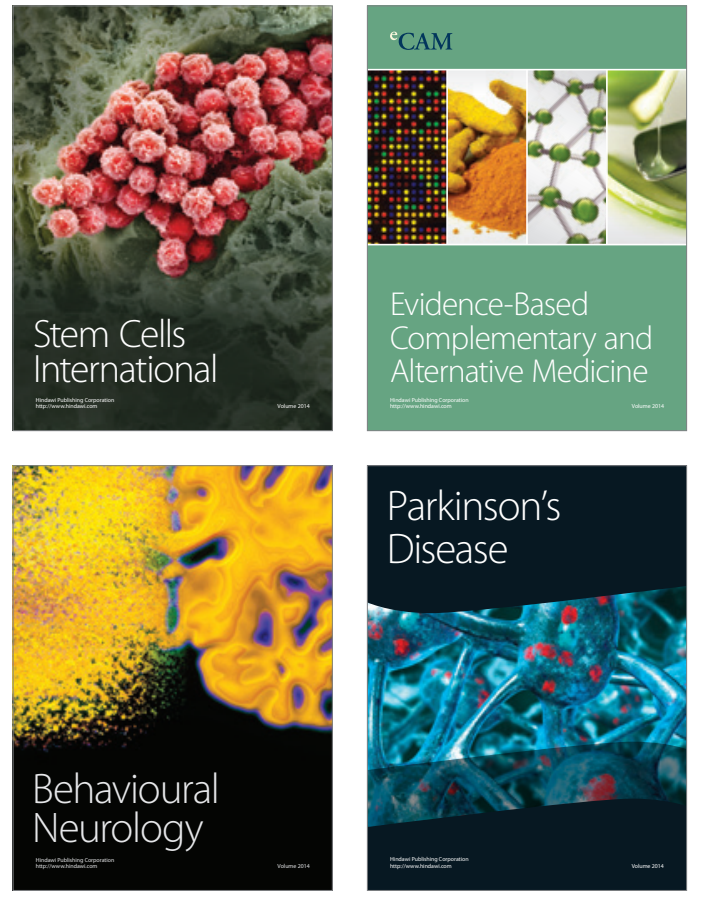
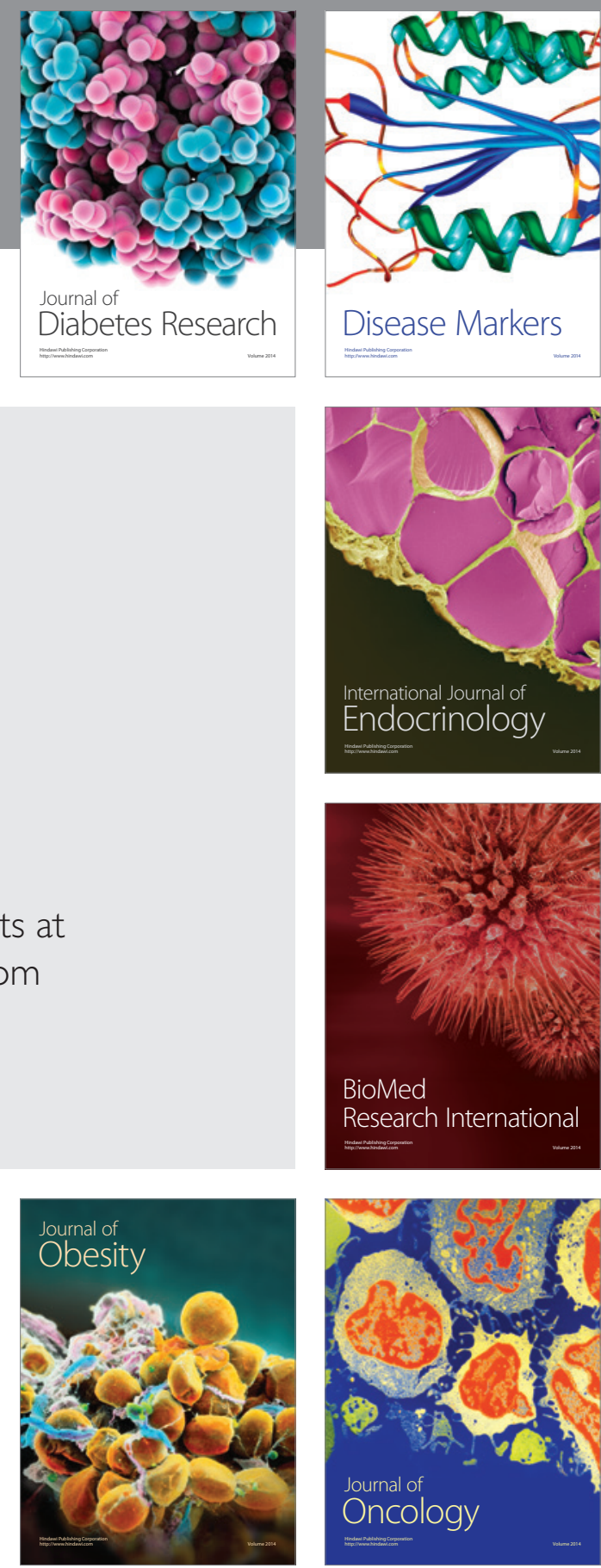

Disease Markers
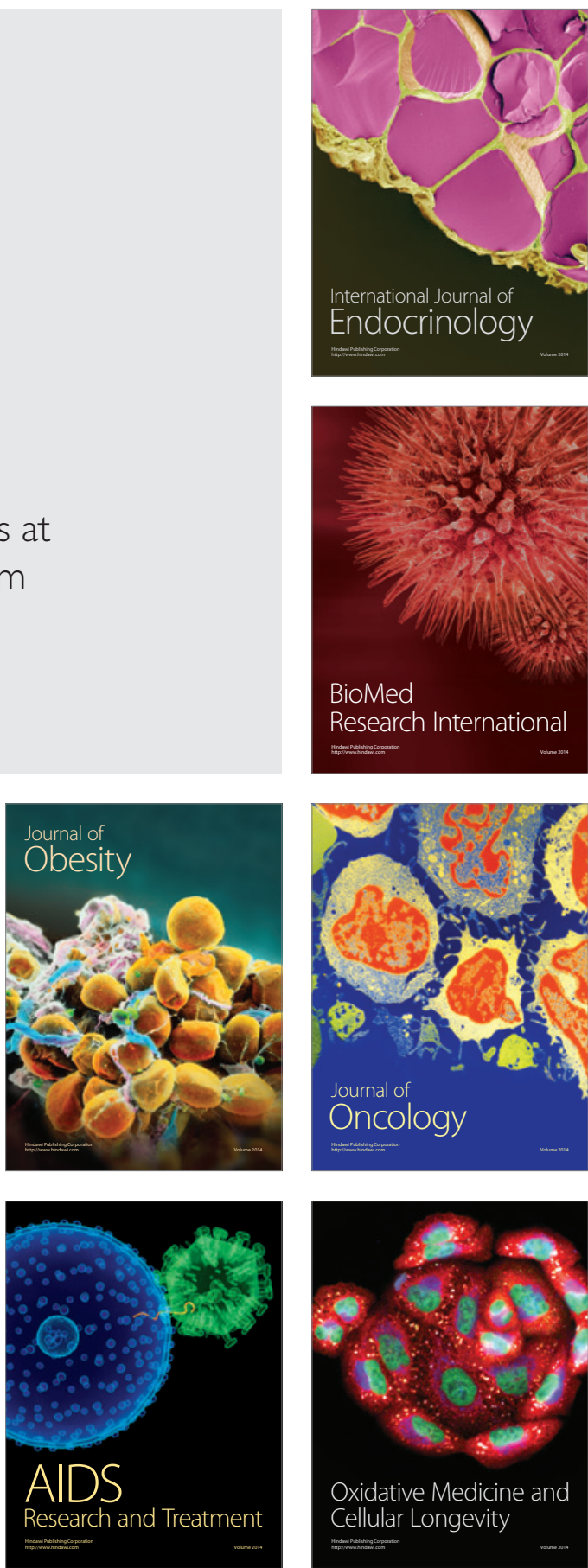